\title{
First report of the Mourning Gecko, Lepidodactylus lugubris (Duméril \& Bibron 1836), from The Bahamas
}

\section{Kenneth L. Krysko and Claudia MacKenzie-Krysko}

'Florida Museum of Natural History, University of Florida, Gainesville, Florida 32611, USA (KLK: kenneyk@ufl.edu)

Date of publication: 30 March 2016.

Citation: Krysko KL, MacKenzie-Krysko C (2016) First report of the Mourning Gecko, Lepidodactylus lugubris (Duméril \& Bibron 1836), from The Bahamas. Caribbean Herpetology 54:1-2.

The Mourning Gecko, Lepidodactylus lugubris (Duméril \& Bibron 1836), is an all-female parthenogenetic species complex with at least six known clones native to the western Pacific and Indian Ocean islands (Yamashiro et al. 2000; Zug 2013). This species has been introduced to many areas around the world (Kraus 2009; Krysko et al. 2011; Hoogmoed \& Avila-Pires 2015), although the only known record of this species in the Caribbean is from Grande Terre, Guadeloupe (Henderson and Breuil 2012). Here, we report it for the first time from The Bahamas.

The island of North Bimini in The Bahamas is known to have seven species of lizards, one of which (Sphaerodactylus argus Gosse 1850) is suspected of being introduced (Buckner et al. 2012). Between 28 February and 2 March 2016, we surveyed the islands of North and South Bimini, The Bahamas. On North Bimini, we inspected the premises of the Bimini Big Game Resort and Marina, Alice Town $\left(25.727001^{\circ},-79.295807^{\circ}\right)$ each night between 1900-2115 h. There, we collected 11 Lepidodactylus lugubris (Fig. 1). Nearly all individuals were found next to lights on walls, but one was captured on the ground. All specimens collected were deposited in the Division of Herpetology (UF-Herpetology), Florida Museum of Natural History, University of Florida (UF 177569-177571, 177579-177584, 177595-177596).

This species was confirmed as Lepidodactylus lugubris diploid clone A, the most common and widespread of the clones (Zug 2013). We are uncertain of its introduction pathway on North Bimini, but it likely arrived as a stowaway on cargo or plants because of the high number of tourists visiting the island, as well as ornamental plants being imported for landscaping.

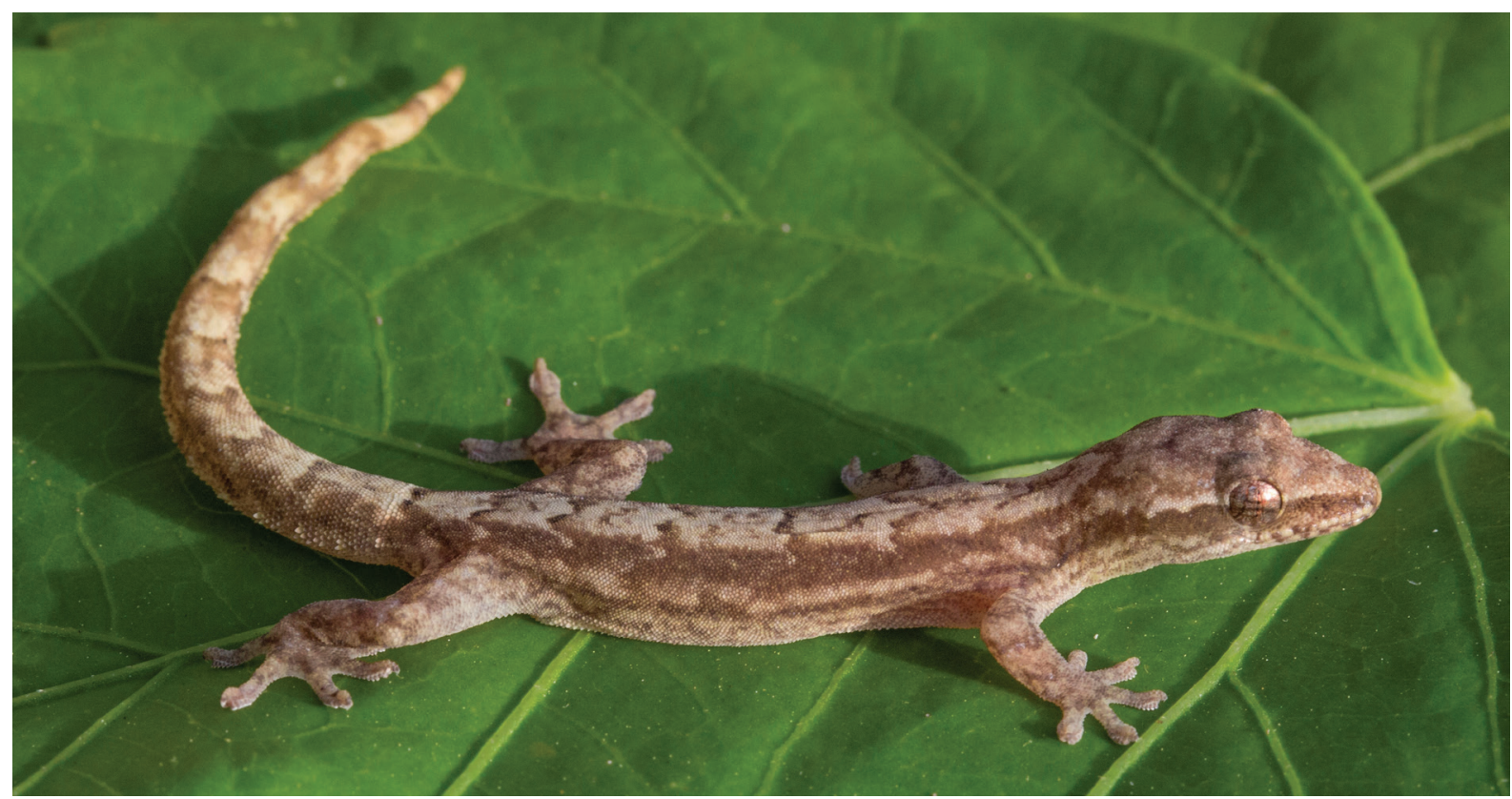

Figure 1. The Mourning Gecko, Lepidodactylus lugubris clone A, from North Bimini, The Bahamas. 


\section{Acknowledgements}

We thank Simeon Pinder, Luceta Hanna, and Oscar Munroe for The Bahamas Department of Agriculture permit (01/2016); Philip S. Weech and Stacy Lubin-Gray for The Bahamas Environment, Science \& Technology (BEST) permit; and Robert Powell, Aaron M. Bauer, Tony Gamble and Louis A. Somma for species confirmation.

\section{References}

Buckner SD, Franz R, Reynolds RG (2012) Bahama Islands and Turks \& Caicos Islands, pp. 93-110. In: Island lists of West Indian amphibians and reptiles, Powell R, Henderson RW (eds), Bulletin of the Florida Museum of Natural History, 51, 85-166.

Henderson RW, Breuil M (2012) Lesser Antilles, pp. 148-159. In: Island lists of West Indian amphibians and reptiles, Powell R, Henderson RW (eds), Bulletin of the Florida Museum of Natural History, 51, 85-166.

Kraus F (2009) Alien Reptiles and Amphibians: A Scientific Compendium and Analysis. Springer, Dordrecht, Netherlands, $563 \mathrm{pp}$.

Krysko KL, Burgess JP, Rochford MR, Gillette CR, Cueva D, Enge KM, Somma LA, Stabile JL, Smith DC, Wasilewski JA, Kieckhefer GN III, Granatosky MC, Nielsen SV (2011) Verified non-indigenous amphibians and reptiles in Florida from 1863 through 2010: outlining the invasion process and identifying invasion pathways and stages. Zootaxa, 3028, 1-64.

Hoogmoed MS, Avila-Pires TCS (2015) Lepidodactylus lugubris (Duméril \& Bibron 1836) (Reptilia: Gekkonidae), an introduced lizard new for Brazil, with remarks on and correction of its distribution in the New World. Zootaxa, 4000, 90-110.

Yamashiro S, Toda M, Ota H (2000). Clonal composition of the parthenogenetic gecko, Lepidodactylus lugubris, at the northernmost extremity of its range. Zoological Science, 17, 1013-1020.

Zug GR (2013) Reptiles and Amphibians of the Pacific Islands: a Comprehensive Guide. University of California Press, Berkeley and Los Angeles, California, USA. 306 pp. 